
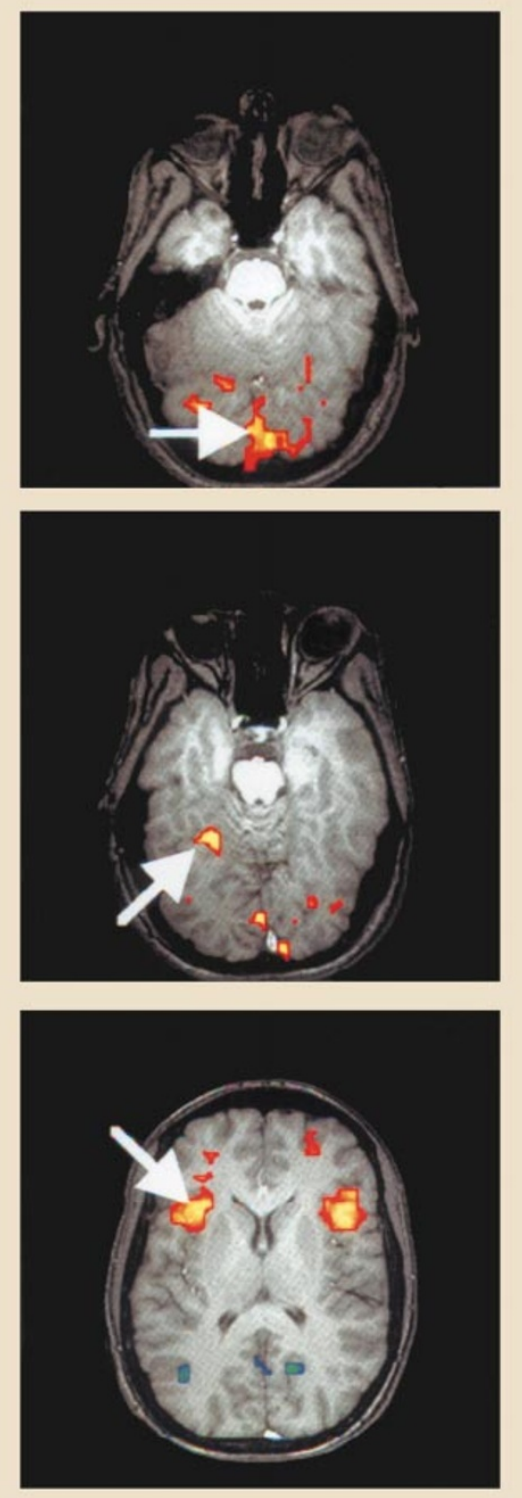

Brain waves: "there is no single 'centre' for attention in the brain".

ters in this part of the book employ a method not discussed in the first section, that is, the approach of cognitive psychology. They focus on the analysis of behaviour itself (the speed and accuracy with which perceptual and cognitive tasks are carried out) in populations of normal people, and draw inferences from the behavioural data about how the brain must be organized.

The topics were selected for their value in illustrating cognitive neuroscientific approaches, and the coverage is therefore somewhat idiosyncratic - readers who desire a broader overview of current theoretical issues in attention research may wish to consult offerings in the "Attention and Performance" series (published by Erlbaum and MIT Press), or Harold Pashler's recent tutorial volume, Attention (Psychology Press, 1998). However, these chapters provide excellent introductions to more than a dozen fascinating problems concerning how the brain exerts control over cognition.

One is always tempted to be dazzled by the technological advances that permit increasingly detailed and, in the case of technologies like functional neuroimaging, aesthetically pleasing measurements of brain function. It is these advances, after all, that have made such rapid progress in cognitive neuroscience possible. However, the takehome message of this volume is that satisfactory progress requires careful attention not just to the brain, but to the behaviour that the brain produces. In chapter after chapter, the authors rely on a detailed analysis of the psychological requirements of behavioural tasks to motivate the design and interpretation of their experiments.

Parasuraman's 1984 publication Varieties of Attention (with D. R. Davies) was a highly influential collection detailing the problems in attention then faced by cognitive psychologists, and it continues to be widely cited. This new volume promises to be even more useful.

Steven Yantis is in the Department of Psychology, Johns Hopkins University, Baltimore, Maryland 21218-2686, USA.

\section{Looking after your molecules}

\section{The Molecules within Us: Our Body in Health and Disease \\ by Charles A. Pasternak \\ Plenum: 1998. 335 pp. $£ 17.55$, \$28.95}

\section{John Emsley}

The traditional groupings in chemistry organic, inorganic, physical and theoretical - have all but dissolved, due mainly to their interactions with outside disciplines. The demands of those in medicine, biology and pharmacology are changing the foci of chemistry, but this meeting of minds has given rise to the creation and investigation of molecules of fascinating complexity. Their cooperation could also have huge medical benefits.

When science moves quickly and promises to impinge on everyday life, it is important to explain to the public what is going on, before the mischief makers get to work. So far their opposition to the healing sciences has been muted, merely emphasizing the side-effects that new drugs and treatments can have, but of late their voice has become more strident, playing on public ignorance about genetic manipulation and encouraging exaggerated fears about what this might lead to.

For these reasons one welcomes Charles Pasternak's book The Molecules within Us, which can be warmly recommended. Pasternak has the expert knowledge and the communicative skills to lead us safely through some of the most complex science that is currently going on. Even though we may soon forget the detail of what he tells us, we are left with a memorable and upbeat message: that molecules are what we are, and that disease is mainly due to their malfunction.

This is a book of solid science, packed with a mixture of the latest advances in the molecular biology of the human body, and leavened with the author's opinions on the human condition as most of us experience it. It is a mixture of scientific explanation that an educated lay person can grasp, and of common sense that most will agree with.

As its title implies, The Molecules within Us is about the basic units that compose the living cell and all the components that go into making us what we are. There are chapters on nutrition and metabolism, genes and the environment, infection and the immune system, stress (an excellent chapter), the workings of the brain (also very good), and ageing and death. Pasternak should now be prevailed on to write a shorter version of his book that can carry its message to an even wider audience.

Pasternak peppers his account with fascinating anecdotes and curious details, such as this: "In Hyderabad, India, asthmatics are lining up to have a small ( 2 inches long) live fish known as a murrel. . . dropped down their throats. . . one fish per year, for three successive years, is said to provide a lifelong cure."

Before we give a condescending smile at the naivety of the above, we should bear in mind that we in the West are not immune to embracing alternative treatments such as homeopathy, herbal medicine, aromatherapy and reflexology. I was disappointed that Pasternak did not take a harder line on alternative medicine, but perhaps he was advised not to do so, as it might have alienated some of his readers. Nevertheless, his seventh chapter, "Orthodox versus Alternative Medicine", finally comes down against it. Yet even scientific medicine is finding it hard to defeat the devils of cancer. While some death rates from cancer are declining, such as cervical and testicular cancer, others are increasing, such as liver, prostate and lung cancer in women (although this can be attributed to smoking).

I warmed to Pasternak's message in his chapter on the causes of diseases, when he dismisses the prevailing idea that strenuous exercise will prolong our lives. He concludes that, "provided we have no major health problems, we should just continue to sit in our armchairs, read the scientific journals and newspapers about startling new discoveries... and go for a walk to buy fresh fruit and vegetables". How comforting it is to find an expert offering such reassuring advice about the lifestyle that many of us have adopted.

This is an excellent book, possibly a little heavy going for the non-scientist, but not for the readers of Nature.

John Emsley is in the Department of Chemistry,

University of Cambridge, Lensfield Road,

Cambridge CB2 1EW, UK. 